\title{
Animal House: Emotional Support Animals in Higher Education and ADA Implications
}

\author{
Victoria Hammill $^{\mathrm{a}}$, Lithda Phattaphone ${ }^{\mathrm{a}}$, Dr. Jennifer Anderson ${ }^{\mathrm{a}}$, Betsy Brandt ${ }^{\mathrm{b}}$
}

\begin{abstract}
The use of service animals as an accommodation for a person with a disability is no longer viewed with uncertainty, and the rise of service animals across a myriad of related health, behavioral health, and education settings speaks to its proclivity.

Conversely, the wide range of ways in which animals can be used for supportive service is not so widely understood. As such, this writing seeks to explore the evolution of service animals, the subsequent changing landscape of higher education, and how the ADA promotes further exploration in this area.
\end{abstract}

Keywords: accommodations, Americans with Disabilities Act, emotional support animals

The use of service animals as an accommodation for a person with a disability is no longer viewed with uncertainty. The rise of service animals across a myriad of related health, behavioral health, and education settings speaks to its proclivity. Conversely, the wide range of ways in which animals can be used for supportive service, whether that be the use of animal-based programming or supportive service, are not so widely understood (Rothstein \& Rothstein, 2009). Animals can be incorporated into an array of supportive and educational programming; however, fall into six (6) categories: service animals, public service animal, therapy animal, visitation animal, sporting and recreational animal, and support animal (Parenti, Foreman, Meade, \& Wirth, 2013).

Within each type of category, there is great variability to the typical level of skills required: advanced, intermediate, and basic. All the categories require the animals to meet standards and/or hold a certification except support animals. Support animals already have various federal regulations that enable them to reside in both private and public housing (Fair Housing Act, 1968; Fair Housing Amendments Act, 1988). As such, this writing seeks to explore the evolution of service, therapy and support animals, the subsequent changing landscape of higher education, and how the ADA promotes further exploration in this area. The work will conclude with a discussion of best practices.

\section{Prevalence of Companion Animals}

Research indicates that of 82.5 million households in the U.S., about $68 \%$ had a pet (American Veterinary Medical Foundation, 2012). With the most popular pet being a dog; next most popular was a cat. In the same survey, $29 \%$ of households reported owning both a dog and a cat, and 30\% of those surveyed owning other pets-fish, birds, small animals, and reptiles (American Veterinary Medical Foundation, 2012). According to the Pew Research Center (2006), it was discovered women more often than men viewed their pet as a family member. Of all individuals surveyed, $90 \%$ were between the ages of 18-29. Additionally, those who defined themselves as single (marital status) tended to view their pet as a family member. Dog owners, more frequently than cat owners, viewed their pet as a family member. When the data is merged, it illustrates the popularity of animals as companions and supports the rise of animals used for service, assistance, and emotional support (Bauman, Davidson, Sachs, \& Kotarski, 2013).

\section{Relevance for Persons with Disabilities}

In the United States, about $25 \%$ of adults experience a mental health impairment, as well as about $5 \%$ of adults having a mental health illness (Von Bergen, 2015). In addition, mental health impairments are common among college students. With $20 \%$ of young adults experiencing a mental health impairment and 30\% of college students selfreporting difficulty in in ability to function due to feeling down (National Association on Mental Illness and the JED Foundation, 2016).

Estimates of the prevalence of mental health problems among undergraduate students varies greatly depending on how the term mental health is defined (Rosenthal \& Wilson, 2016). Creating a less restrictive definition where mental health symptoms were defined as indicators of a departure from normal function or feeling is recommended (Albright, Fletcher, Pelts, \& Taliaferro, 2017). Studies have determined symptoms of emotional distress persist throughout the college years (Rosenthal \& Wilson, 2008), while conversely, there is an underutilization of available services within this age group (Hunt \& Eisenberg, 2010).

Additionally, there are undergraduate students who present with disabilities. According to the US Equal Employment Opportunity Commission (2015), a disability is defined as "a person who has a physical or mental impairment that substantially limits one or more major life activity, has a record of such an impairment, or is regarded as having such an impairment" (Section 4, para.1). Research done for the 2011-2012 academic year (U.S. Department of Education, 2016), found that about $11 \%$ of undergraduate students selfreported having a disability, with this study defining disability as either a physical or mental disability. Interestingly when looking at disability rates of veteran students, it is noticed that about $20 \%$ of students self-reported having a disability (Snyder, DeBrey, \& Dillow, 2015). Further confounding these trends, Molina and Morse (2015) report that successful support for military and veteran-connected college students are not well understood despite record levels of enrollment.

With relation to support animals on college campuses, it has been asserted that "the single biggest concern on the part of institutions...would be setting a precedent. Universities

a. Department of Social Work, University of Wisconsin at Whitewater, Whitewater, WI, 53190

b. Center for Students with Disabilities, University of Wisconsin at Whitewater, Whitewater, WI, 53190

Correspondence: Victoria Hammill hammillvl20@uww.edu; Lithda Phattaphone phattaphl18@uww.edu 
worry that if they say yes to this one, they won't be able to say no to the next one" (Field, 2006, p.15). It has been encouraged that animals (service, support, and therapy) become integrated into research (Beck et al, 2012), into social work education (Tedeschi, Fitchett, \& Molidor, 2005), and across various settings "because of their interconnectedness with humans" (Risley-Curtiss, 2010, p. 39).

\section{College Students with Disabilities}

The number of students registering with disability services is growing on many campuses (Zalanick, 2016). According to Gordon and Keiser (2000), the Americans with Disabilities Act (ADA) stresses two primary areas of consideration for higher education: whether a student has a qualifying disability and whether the requested accommodations are reasonable. With the continuous growth of students registering with disability services, there is a need to consider accessibility in every area (i.e. policies, procedures, architecture); the ADA applies to all collegesponsored activities, including those both on and off campus (Barger, 2016). Any college in the United States who receives federal funds are encouraged to consider students in need of specific accommodation(s) to aid with housing and education on campus (Barger, 2016); however, institutions are not required to make fundamental changes to existing programs nor are they required to make any changes that would impose an undue hardship to the university. For that reason, essential academic requirements do not need to be modified (McCleary-Jones, 2005).

Higher education institutions who are flexible with accommodating students with a disability require a submission of an application to see whether a student qualifies for specific academic and housing accommodations. To obtain specific academic accommodations, students are typically required to fill out an application for disability services and provide documentation of the disability(s). Documentation from a qualified professional (i.e. medical doctor, neuropsychologist) is needed to show proof of any disability(s).

Students are often assigned to a disability services professional at the institution to determine appropriate accommodations. This is done through reviewing the student's application, documentation, previous services, and other pertinent information the student provides. If it is part of the college's process, this can include information from a meeting with the student. The institution is required to provide qualifying services; however, not necessarily in the student's preferred manner (Wilcox, Winn, \& Fyvie-Gauld, 2005). For example, having tests read may be an approved accommodation. The student may want a live reader, but as long as the tests are read, the institution can have the tests read by a computer program rather than a human being. Cost cannot be used to deny an accommodation, but "reasonable workarounds are acceptable" (Barger, 2016, p. 42).

Each student is given an individual accommodations plan. Providing accessibility and accommodations in a higher education setting can be challenging. Lee (2014) asserts four central issues that have involved litigation with students with disabilities. The first central issue is the accessibility of ereaders and other technology for students with a visual impairment. Second issue centers on students with mental health diagnoses obtaining permission for a comfort animal, which is known as an emotional support animal. This request is for a comfort animal can be both on campus and/or even to class. The third central idea pertains to the requirements placed on colleges "to exclude students who may be a danger to themselves" (Lee, 2014, p.41). These requirements have become more stringent. Lastly, students with disabilities have begun to challenge dismissal from a program when they performed excellently in the classroom setting but struggled in the more hands-on learning that occurs in the graduate level.

As institutions continue along the path of providing access for students with disabilities, a balance must be struck between student accessibility, animal well-being, the campus community and its resources. This can be challenging in a time when institutions of higher education are working with smaller budgets and increased enrollment of students with disabilities. Higher education institutions would need to create their own policies regarding the use of animals. These policies would need to follow the baseline provided by federals acts that set a minimum standard.

\section{Policies and Legislation}

There are many policies and pieces of legislation that come into play when regarding disabilities and the accommodations that are available to a person with a disability. The Americans with Disabilities Act of 1990, the Americans with Disabilities Amendments Act of 2008, and the Fair Housing Act are significant acts. Each act plays its own role, but they also intertwine to create the rules and regulations that are known and used today, including the accommodations for using emotional support animals within higher education.

\section{Americans with Disabilities Act}

In 1990, the Americans with Disabilities Act (ADA) was signed into law by President George H.W. Bush. This law prohibits discrimination against people with disabilities and ensures they have the access to the same opportunities as other citizens. A few years after the implementation of the Americans with Disabilities Act, authorities mentioned that the Amendments Act of 2008 was passed to include an expansive definition of "disability" and state who is covered under the ADA law.

According to the ADA (2018), in order for an individual to be covered by the ADA, there must be documentation for the disability. The standards for determining if an individual has a disability are as follows: Physical or mental impairment that substantially limits one or more major life activities; has a record or history of such an impairment; and is perceived by others as having such an impairment (McCleary-Jones, 2005, p. 25). Disabilities are both visible and invisible and can range from anxiety and depression to quadriplegia and traumatic brain injuries. The Amendments Act of 2008 provided more definition as to what a major life activity is; however, there is still some variability in making that determination-students may choose not to report that they have a disability. Major life activities are meant to be illustrative and not all-inclusive (Taylor, 2009) and it continues to broaden the scope of ADA coverage (Victor, Thacker, Gary, Pawluk, \& Copolillo, 2017). 


\section{Fair Housing Act}

On September $13^{\text {th }}, 1988$, the Fair Housing Act was signed into law and became effective on March 12, 1989. The Fair Housing Act states that discrimination is prohibited based off of "race, color, religion, sex, or national origin related to housing" (United Spinal Association, 2004, pg. 1). This act is also applicable to individuals with a disability. It includes a provision that landlords must make reasonable modifications for people with disabilities, which may include making exceptions to policies and procedure. For example, a no-pets allowed location may need to allow service animals (Schoenfeld-Tacher, Hellyer, Cheung, \& Kogan, 2017). In 2011, U.S.C.A. \& 36.104, clarified the types of housing that were covered under the Fair Housing Act. This clarification specifically included university housing.

Currently, animals that can be considered service animals are dogs or miniature horses (Topinka, Nichols, \& Brooks, 2016). They must be "individually trained to do work or perform tasks for an individual with a disability" (Department of Justice, 2015, p. 1). It includes a provision for animals that "provide emotional support to alleviate a symptom or effect of a disability" (Department of Justice, 2015, p. 7). The Department of Justice (2015) goes on to clarify that service animals must perform a task (or tasks) that are directly related to the individual's disability and that service animals are allowed wherever the public is allowed to go. In addition, the DOJ states the "...definition does not affect or limit the broader definition of 'assistance animal' under the Fair Housing Act" (Department of Justice, 2011, p.2). Some states and localities have broader definitions.

In comparison between the ADA and the Fair Housing Act, the ADA "makes a distinction between psychiatric services animals and emotional support animals" (Department of Justice, 2015, p. 2). The ADA includes only animals that provide some sort of action. For example, a dog that is trained to take a specific action to avoid or alleviate an anxiety attack (Department of Justice, 2015). Some state and local laws also give Emotional Support Animals more access than the ADA. Due to the complexity of the laws surrounding service and emotional support animals, there is often a need for the laws to be interpreted by the legal system (Ligatti, 2010). Disability laws are continually being updated, revised and developed. This maze of laws can be difficult for colleges and universities trying to determine appropriate accommodations for students with disabilities.

\section{Animals as Supports}

Animal-assisted therapy (AAT) is a complementary goal-directed intervention using animals, usually dogs trained to be obedient, calm, and comforting, for therapeutic benefits across a broad range of medical, mental, and behavioral conditions (Marcus, 2013). Key considerations of AAT include specified goals and objectives for each individual and the measurement of the progress of those goals. Significant results have shown that AAT is affective across a wide variety of clinical areas - mental health, health care, behavioral health, and educational settings (Kogan, Schaefer, Erdman, \& Schoenfeld-Tacher, 2016). There are six interconnected benefits of AAT and that includes: (1) positive behavior patterns (Komorsky \& O'Neal, 2015), (2) trust, (3) caring for others (Adams, Sharkin, \& Bottinelli, 2017), (4) empathy (Van Twembeke \& Goeman, 2018), (5) cooperation and responsibility (Hensley \& Tallichet, 2005), and (6) unexpected benefits such as, pain management and comforting support (Firmin et al, 2016).

Furthermore, there are unique considerations when implementing animals into therapeutic programs. First, animals can be transportable to where consumers are located at the time of needed interventions and supports. Second, the same animal also can be used for different treatment objectives across multiple consumers and within multiple programs. Third, advanced training in animal behavior is required, such as animal training techniques, understanding of animal behavior/physiology, and animal care skills, but not limited to soft skills (such as the clinical application of facilitating human-animal interactions and strategies for integrating animal supports with general counseling skills). Lastly, practitioners integrating animals into their work must go beyond facilitating a safe animal interaction - they must be able to facilitate and interpret those interactions in a therapeutically meaningful way, must obtain appropriate training and supervision, and that currently lacks any formal guidelines about the ethical treatment of therapy animals (American Counseling Association, 2014). Although appropriate counselor training may help reduce the risk for therapy animal exploitation, the current lack of counselingspecific ethical codes regarding the treatment of therapy animals highlights another significant area for professional advocacy.

\section{Emotional Support Animals}

The use of animals for emotional support is a different take on the same therapeutic process with its own unique considerations as well. While AAT has those goals and objectives for each individual, emotional support animal (ESA) users may just need interaction when experiencing stress, while other users may seek this interaction on a daily basis as a way to enhance quality of life. Historically, emotional support animals were referred to as simply companion animals (Risley-Curtis, 2010). However, the distinction between a companion animal and an emotional support animal is the ability to provide psychological benefits to the owner without formal training to do so.

Due to the idea that a companion animal can also be an emotional support animal, this animal does not have to be a dog. An emotional support animal can also be, but is not limited to, a cat, a rabbit, a guinea pig, or even a pot-bellied pig. An ESA does not have to be trained to perform any particular task. To qualify to have an emotional support animal, the person seeking the assistance must have a disability and can be verified by a professional (Wisch, 2015). This verification is required due to the disability being either physical or mental.

There is an expansive list of reasons why emotional support animals are beneficial. Emotional support animals have the ability to help people who have depressive disorders by assisting them in interacting with others. Emotional support animals are also keen in their ability to reduce anxiety (Bourland, 2009). Additionally, it has been shown that the use of emotional support animals can help persons who struggle with mood disorders to major neurological considerations because the animals help alleviates stress by increasing socialization and decreasing agitated behaviors (Baun \& McCabe, 2003). 


\section{Unique Considerations}

There are considerations that need to be taken account for when the use of emotional support animals in play. These considerations are unique to each individual, as well as the situation. It is imperative that each person and situation is treated on an individual basis to ensure that optimum amount of accommodation is obtained. These considerations include housing, awareness, policy and protocol.

Housing. Housing becomes a unique consideration for both the student with disabilities as well as the emotional support animal. The Office of Fair Housing and Equal Opportunity states that a housing provider is not allowed to deny the request for an emotional support animal due to the assumption that the disability is not apparent. On the contrary, the provider can ask for the verification, but is not allowed to ask specifics regarding any disability. This verification is merely proof from a professional such as a physician, psychiatrist, social worker, or any other mental health professional assist in reducing or alleviating any symptoms that are being suffered (U.S. Department of Housing and Urban Development, 2013).

Increased Awareness. Today, awareness on the benefits of emotional support animals is on the rise. Some might say that there is nothing more powerful than the human-animal connection. Animals have become more than just guide dogs. Simply petting an animal is proven to lessen the symptoms of anxiety and depression (McSweeney, 2014). Emotional support animals, otherwise known as ESA's, are typically dogs and cats, but may include other animals of any species that provide support, well-being, comfort, aid, or a calming influence through companionship, non-judgmental positive regard, affection, and a focus in life simply by being close to their handler (Von Bergen, 2015). This is an interaction that many people feel they cannot receive from other humans. Animals seem to understand us in a way that makes us feel accepted. The presence of these animals alone may relieve and/or help reduce psychologically or emotionally induced pain.

Popularity and Protocol. Emotional support animals can be seen in a wide variety of different locations and settings. There is a myriad of ways a consumer might benefit from the use of an emotional support animal. Just as there are a myriad of ways a consumer might employ their emotional support animal, there exists a myriad of policies related to employment ranging from travel, to housing, and into the realm of education. ESAs do not qualify as service animals under the Americans with Disabilities Act (ADA), but they may be permitted as reasonable accommodations for persons with disabilities under the Fair Housing Act (Fair Housing Act (42 U.S.C. Part 3604) and Air Carrier Access Act (ACAA) and C.F.R. Part 382.117).

Higher Education is full of possibilities and emerging protocols when it comes animal-based programming and animal-based accommodations. This becomes especially true when considering the prevalence of companion animals and the growing range of emotional, intellectual, and behavioral needs of college students.

\section{Best Practices within Higher Education}

Developing and maintaining relationships with animals in human lives are important (Tedeschi, Fitchett, Molidor, 2005). The ability to develop a relationship with a domestic animal allows people of all ages to feel a sense of security and unconditional love (Risley-Curtiss, 2010). Undergraduate students who are diagnosed with a mental health disorder or who present a disability may benefit from the continual support of having an animal as a companion. A plethora of studies support the idea of utilizing domestic animals to heighten the quality of life for individuals who are immobilized to independence (Risley-Curtiss, 2010).

Today, numerous elementary schools and universities approve the right for students to have a companion animal in school settings. The Department of Justice validates the need of service animals for students with a mental health disorder and/or student who has a disability; however, there are limitations to devise this regulation. The terms service animal and comfort animal have a commonality in alleviating stress and anxiety among students, but the meaning behind each term lacks clarity and unity. According to The Department of Justice, a service animal is described as "any [animal] that is individually trained to do work or perform tasks for the benefit of an individual with a disability" (Lee, 2014, p. 42). Service animals aid in everyday tasks such as pulling a wheelchair, retrieving items, alerting the owner when medicine needs to be taken, as well as to guide the person to and from different places. According to Katsiyannis \& Berry (2011), Section 504 Regulations, $§ 104.44$, a service animal is allowed in any place that the handler may need to enter, except for instances in which the animal's presence interferes with the handler's safety. Conversely, a comfort animal is not trained, but reassures and comforts students with a disability or a mental health disorder. Multiple schools and universities are open to accepting service animals on school grounds and in residence halls upon request; however, the dispute to approve comfort animals on campus is uncertain (Lee, 2014).

Service animals, therapy, and support animals ignite positive attributes in a campus setting, nonetheless, there are concerns for students who don't require the presence of a companion animal. A main concern that is brought to light is the possibility of suitemates, roommates, or nearby residents contracting allergies. Though the owner is "responsible for the care and control of their companion, those who encounter the animal may have a reaction to the animal's dander" (Lee, 2014, p.42). Animal preservation is required by university regulations. Well-groomed and healthy support animals cause less distress to other students in the classroom (Von Bergen, 2015). Many universities also require that support animals must be on a leash; if any of these regulations are violated, then the university has the right to ask the student to remove their companion animal (Von Bergen, 2015). Other concerns that arise are phobias - there may be a fear of dogs, cats, or even reptiles.

Consideration of accommodating students with a mental health disorder or students who have a disability in residence halls is inevitable; however, the accommodation could be applicable in classroom settings. Though there are limitations, many postsecondary institutions accommodate students as much as possible by "following service animal etiquette" (Huss, 2015, p. 443). Service animal etiquette are some guidelines that the student, support animal and university must follow to ensure awareness of students who require the service of a companion animal. Many schools have a requirement where students must submit a request form to have a service animal (Lee, 2014). Higher education 
institutions must screen a student before the start of AAT to protect the student and the therapy and/or emotional support animal. The most important guideline is educating students about support animals. Animal assisted therapy programs have a responsibility to consider the health and welfare of students, therapy and emotional support animals, and others who may encounter an animal in their institution (Stewart, Chang, \& Rice, 2013). Students without a support animal must not engage with the animal nor should students ask questions referring to the use of the support animal. It is crucial that students only interact with the student rather than the support animal.

\section{Conclusion}

When animals are considered as being at an equal level, such as a companion or partner, the emotional needs of the human counterpart more fulfilled (Rosenkoetter, 1991). Additionally, animals have the ability to aid in learning, offer comfort, induce a sense of safety, and improve self-esteem. The use of animals in accommodations has been on the rise over the years. This is due to the extreme benefits animals can provide through the therapeutic process (O'Callaghan \& Chandler, 2011; Wilcox, Winn \& Fyvie-Gauld, 2005).

Disability laws are frequently being changed and updated. Current laws such as the Fair Housing Act and the Americans with Disabilities Act allow students the right to have a service animal within higher education settings; however, the process to be accommodated with a service animal is tedious. Due to the tedious process, students feel discouraged and could terminate the potential use of services (Von Bergen 2015).

Research suggests there are powerful relationships between humans and companion animals (Catanzaro, 1984). Certainly, Animal-Assisted Therapy is being used in schools, hospitals, and mental health settings (Firmin, Brink, Firmin, Grigsby, \& Trudel, 2016) and it has begun to be integrated into programs and services within institutions of higher education (Kogan, Schaefer, Erdman, \& Schoenfeld-Tacher, 2016). Helping professionals are likely to work with individuals and families with companion animals; therefore, it is essential for the inclusion of animals in both practice, research, and education. Educators and educational researchers may only have basic knowledge of the negative and positive relationships between humans and companion animals (Risley-Curtiss, 2010) and as such, may miss out on how emotional support animals can be natural supports for students with disabilities seeking a college education (Adams, Sharkin \& Bottinelli, 2017; Van Twembeke \& Goeman, 2018).

\section{References}

Adams, A. C., Sharkin, B. S., \& Bottinelli, J. J. (2017). The Role of Pets in the Lives of College Students: Implications for College Counselors. Journal of College Student Psychotherapy, 31(4), 306-324.

Albright, D. L., Fletcher, K. L., Pelts, M. D., \& Taliaferro, L. (2017). Use of College Mental Health Services among Student Veterans. Best Practice in Mental Health, 13(1), 65-79.

American Counseling Association. (2014). ACA code of ethics. Retrieved from
http://www.counseling.org/Resources/aca-code-ofethics.pdf

American Veterinary Medical Foundation. (2012). U.S. Pet Ownership Statistics. Retrieved from https://www.avma.org/KB/Resources/Statistics/Pag es/Market-research-statistics-US-petownership.aspx

Barger, T.S. (2016). ADA compliance across the campus. University Business, 197, 41-44

Bauman, M., Davidson, D.L., Sachs, M.C., \& Kotarski, T. (2013). Service, comfort, or emotional support? The evolution of disability law and campus housing. The Journal of College and University Student Housing, 49(1), 142-157.

Baun, M.M., \& McCabe, B.W. (2003). Companion animals and persons with dementia of the Alzheimer's type: Therapeutic possibilities. American Behavioral Scientist, 47(1). 42-51.

Beck, C., Gonzales, F., Sells, C., Jones, C., Reer, T., Wasilewski, S., \& Zhu, Y. (2012). The effects of animal-assisted therapy on wounded warriors in an occupational therapy life skills program. The Army Medical Department Journal, 1, 38-45.

Bourland, K. M. (2009). Advocating change within the ADA: The struggle to recognize emotional-support animals as service animals. University of Louisville Law Review 48(1), 197-220.

Catanzaro, T. E. (1984). The human-animal bond in military communities. In R. K. Anderson, B. L. Hart, \& L. A. Hart (Eds.), The pet connection (pp. 341-347). Philadelphia, PA: University of Pennsylvania Press.

Fair Housing Act of 1968, 42 U.S.C.A. §§ 3601-3631.

Fair Housing Amendments Act of 1988, 24 C.F.R. $\$ 100$.

Field, K. (2006, October 13). These student requests are a different animal. Chronicle of Higher Education, 53(8), 15 .

Firmin, M. W., Brink, J. E., Firmin, R. L., Grigsby, M. E., \& Trudel, J. F. (2016). Qualitative Perspectives of an Animal-Assisted Therapy Program. Alternative \& Complementary Therapies, 22(5), 204-213.

Gordon, M., \& Keiser, S. (Eds.). (2000). Accommodations in higher education under the Americans with Disabilities Act (ADA): A no-nonsense guide for clinicians, educators, administrators, and lawyers. DeWitt, NY: GSI Publications.

Hensley, C., \& Tallichet, S. E. (2009). Childhood and adolescent animal cruelty methods and their possible link to adult violent crimes. Journal of Interpersonal Violence, 24, 147-158

Hunt, J. \& Eisenberg, D. (2010). Mental health problems and help-seek behavior among college students. Journal of Adolescent Health. 46(1). 3-10.

Huss, R.J. (2012). Canines on campus: Companion animals at postsecondary educational institutions. Mo. L. Rev., 77, 418-478.

Katsiyannis, A. \& Berry, J. (2011). Service animals with disabilities under idea and section 504 of the rehabilitation act of 1973. Intervention in School and Clinic, 47(5), 312-315

Kirnan, J., Siminerio, S., \& Wong, Z. (2016). The Impact of a Therapy Dog Program on Children's Reading Skills 
and Attitudes toward Reading. Early Childhood Education Journal, 44(6), 637-651.

Kogan, L. R., Schaefer, K., Erdman, P., \& SchoenfeldTacher, R. (2016). University Counseling Centers' Perceptions and Experiences Pertaining to Emotional Support Animals. Journal of College Student Psychotherapy, 30(4), 268-283.

Komorosky, D., \& O'Neal, K. K. (2015). The development of empathy and prosocial behavior through humane education, restorative justice, and animal-assisted programs. Contemporary Justice Review, 18(4), 395-406.

Lee, B.A. (2014). Students with disabilities: Opportunities and challenges for colleges and universities. Change: The Magazine of Higher Learning. 46(1). 40-45.

Ligatti, C. C. (2010). No training required: The availability of emotional support animals as component of equal access for the psychiatrically disabled under the fair housing act. Thurgood Marshall Law Review. 35(2), 139-168.

Marcus, D. (2013). Impact of animal-assisted therapy for outpatients with fibromyalgia. Pain Medicine, 14(1), 43.

McCleary-Jones, V. (2005) The American with Disabilities Act of 1990 and its impact on higher education and nursing education. ABNF Journal (Association of Black Nursing Faculty). 16(2), 24-27.

McSweeney, F. (2014). 'Moving In': Difficulties and Support in the Transition to Higher Education for In-service Social Care Students. Social Work Education, 33(3), 317-337.

Molina, D., \& Morse, A. (2015). Military-connected undergraduates: Exploring differences between National Guard, reserve, active duty, and veterans in higher education. Washington, DC: American Council on Education and NASPA - Student Affairs Administrators in Higher Education.

National Alliance on Mental Illness and the JED Foundation. (2016). Starting the conversation: College and your mental health. Retrieved from National Alliance on Mental Health: Retrieved from https://www.nami.org/collegeguide/download

O'Callaghan, D.M., \& Chandler, C.K. (2011). An Exploratory Study of Animal-Assisted Interventions Utilized by Mental Health Professionals. Journal of Creativity in Mental Health, 6(2). 90-104.

Parenti, L., Foreman, A., Meade, B.J., \& Wirth, O. (2013). A revised taxonomy of assistance animals. JRRD, 50(6), 745-756.

Pew Research Center (2006). Gauging family intimacy: Dogs edge cats (Dads trail both): A social trend. Washington, D.C.: Author Retrieved from http://www.pewsocialtrends.org/files/2010/10/Pets. pdf

Risley-Curtiss, C. (2010). Social work practitioners and the human-companion animal bond: A national study. Social Work, 55(1), 38-46.

Rosenkoetter, M. M. (1991). Health promotion: The influence of pets on life patterns in the home. Holistic Nursing Practice, 5, 42-51
Rosenthal, B. \& Wilson, W.C., (2008). Mental health services: Use and disparity among diverse college students. Journal of American College Health. 57(1). 61-68.

Rosenthal, B.S. \& Wilson, W.C. (2016). Psychosocial dynamics of college students' use of mental health services. Journal of College Counseling, 19, 194204.

Rothstein, L., \& Rothstein, J. (2009). Disabilities and the law (4th Ed.). Eagan, MN: Thomson Reuters.

Schoenfeld-Tacher, R., Hellyer, P., Cheung, L., \& Kogan, L. (2017). Public perceptions of service dogs, emotional support dogs, and therapy dogs. International Journal of Environmental Research and Public Health. 14, 1-13.

Snyder, T., de Brey, C., \& Dillow, S. (2015). Digest of education Statistics. National Center of Education Statistics.

Stewart, L.A., Chang, C.Y., \& Rice, R. (2013) Emergent theory and model of practice in animal-assisted therapy in counseling. Journal of Creativity in Mental Health, 8(4), 329-348.

Taylor, B.C. (2009) Court interpretations of major life activities under the ADA: What will change after the ADA Amendments Act? (Report No. 10) Chicago, IL: Great Lakes DBTAC ADA Center.

Tedeschi, P., Fitchett, J., \& Molidor, C.E. (2005). The incorporation of animal-assisted interventions in social work education. Journal of Family Social Work, 9(4), 59-77.

Topinka, J.B., Nichols, J., \& Brooks, M. (2016). Service animals: A new legal dimension within the US military. The United States Army Medical Department Journal. 108-111

United Spinal Association. (2004). Understanding the Fair Housing Amendments Act: A publication of United Spinal Association. Retrieved from https://www.unitedspinal.org/pdf/fair_housing_ame ndment.pdf

U.S. Equal Employment Opportunity Commission. (2015). ADA Amendments Act of 2008. Retrieved from U.S. Equal Employment Opportunity Commission: https://www.eeoc.gov/eeoc/history/ada25th/adaaa.cf $\mathrm{m}$

U.S. Department of Education, National Center for Education Statistics. (2016). Digest of Education Statistics, 2015 (2016-014), Chapter 3. Retrieved from https://nces.ed.gov/fastfacts/display.asp?id=60

U.S. Department of Housing and Urban Development, Office of Fair Housing and Equal Opportunity. (2013). Service animals and assistance animals for people with disabilities in housing and HUD-funded programs (FHEO Notice: FHEO-2013-01). Retrieved from https://www.animallaw.info/sites/default/files/FHE O_notice_assistance_animals2013.pdf

U.S. Department of Justice. (2011). Service Animals. Retrieved from http://www.ada.gov/service_animals_2010.htm

U.S. Department of Justice, Civil Rights Division. (2015). Frequently asked questions about service animals and the ADA. 1-9. Retrieved from 
https://www.ada.gov/regs2010/service_animal_qa.p df

Van Twembeke, E., \& Goeman, K. (2018). Motivation gets you going and habit gets you there. Educational Research, 60(1), 62-79.

Victor, C.M., Thacker, L.R., Gary, K.W., Pawluk, D.T., \& Copolillo, A. (2017). Workplace discrimination and visual impairment: A comparison of Equal Employment Opportunity Commission Charges and resolutions under the Americans with Disabilities Act and the Americans with Disabilities Amendments Act. Journal of Visual Impairment \& Blindness. 111(5). 475-482.

Von Bergen, C.W. (2015). Emotional support animals, service animals, and pets on campus. Administrative Issues
Journal: Connecting Education, Practice, and Research, 5(1), 15-34.

Wilcox, P., Winn, S., \& Fyvie-Gauld, M. (2005). 'It was nothing to do with the university, it was just the people': the role of social support in the first-year experience of higher education. Studies in Higher Education, 30(6), 707-722.

Wisch, R.F. (2015). FAQs on emotional support animals from Michigan State University College of Law. Retrieved from Animal Legal \& Historical Center: https://www.animallaw.info/article/faqs-emotionalsupport-animals\#s1

Zalaznick, M. (2016). Blending academic instruction and life lessons. University Business, 19(1), 36-40. 